\title{
A reprint from
}

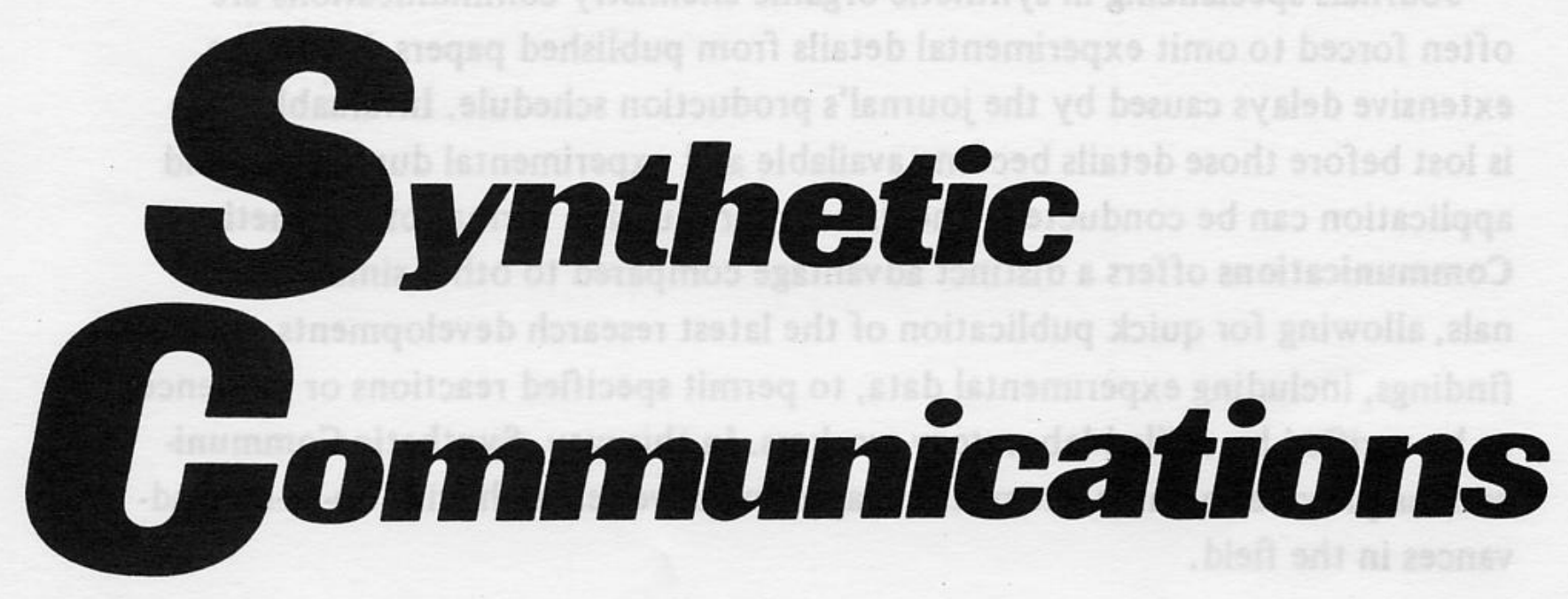

An International Journal for

Rapid Communication of Synthetic Organic Chemistry 


\section{Synthetic Communications}

Journals specializing in synthetic organic chemistry communications are often forced to omit experimental details from published papers due to the extensive delays caused by the journal's production schedule. Invaluable time is lost before those details become available and experimental duplication and application can be conducted. The direct reproduction format of Synthetic Communications offers a distinct advantage compared to other similar journals, allowing for quick publication of the latest research developments and findings, including experımental data, to permit specified reactions or sequences to be verified by skilled laboratory workers. In this way, Synthetic Communications provides organic chemists engaged in active research with up-to-date advances in the field.

To complement its rapid and inclusive publishing format, Synthetic Communications presents timely and extensive coverage of a broad range of topics, ranging from the synthesis of natural products and related intermediates to the synthesis and utilization of new reagents for functional group interconversions. Featuring thorough, in-depth reporting on new experimental methods and reagents pertaining to synthetic organic chemistry, each paper in this outstanding journal is profusely illustrated with references, graphs, and structural formulas, simplifying the task of organizing and processing the new information contained in each issue.

With its exhaustive coverage, swift lab-to-print format, and comprehensive presentation, Synthetic Communications stands as the journal to which every organic chemist should have immediate access.

For subscription information write to:

Promotion Department Marcel Dekker, Inc. 270 Madison Avenue New York, N.Y. 10016 


\title{
A SIMPLE ONE-POT SYNTHESIS OF FUNCTIONALIZED KETIMINES FROM KETONES AND AMINE HYDROCHLORIDE SALTS
}

\author{
Maurizio Selva ${ }^{*}$, Pietro Tundo, Carlos A. Marques \\ Dipartimento di Scienze Ambientali dell'Universita' di Venezia \\ Calle Larga S. Marta, 2137 - 30123 Venezia, Italy
}

\begin{abstract}
Functionalized ketimines of the general formula $\mathrm{RR}^{\prime} \mathrm{C}\left(=\mathrm{NCH}_{2} \mathrm{Y}\right)[\mathrm{R}$ and $\mathrm{R}^{\prime}=\mathrm{Ph}$, alkyl; $\mathrm{Y}=\mathrm{CN}$ (1), $\mathrm{CH}_{2} \mathrm{Cl}$ (2), COOMe (3)] have been prepared by the condensation of ketones with the corresponding primary amine hydrochloride salts $\left[\mathrm{NH}_{2} \mathrm{CH}_{2} \mathrm{CN} \cdot \mathrm{HCl}\right.$ (4), $\mathrm{NH}_{2} \mathrm{CH}_{2} \mathrm{CH}_{2} \mathrm{Cl} \cdot \mathrm{HCl}$ (5) and $\mathrm{NH}_{2} \mathrm{CH}_{2} \mathrm{COOMe} \cdot \mathrm{HCl}$ (6), respectively]. The reported reaction proceeds mildly in a single step without the need of a previous isolation of the free amine from its salt. N,N-Dimethylformamide (DMF) is used as the solvent and $\mathrm{TiCl}_{4}$ as the drying agent.
\end{abstract}

The synthesis of ketimines is often accomplished by the direct condensation of ketones with primary amines: this reversible reaction can be forced towards products by azeotropic distillation of the formed water $^{1}$ or using drying-catalyst agents such as $\mathrm{TiCl}_{4}{ }^{1 \mathrm{a}, 2}, \mathrm{BuSnCl}_{2}{ }^{3}, \mathrm{Al}_{2} \mathrm{O}_{3}{ }^{4}$ and molecular sieves ${ }^{5}$. Also, ketimines can be prepared by the reaction of ketones with different iminating agents such as $\mathrm{PhN}\left(\mathrm{AlCl}_{2}\right)_{2}{ }^{6}, \mathrm{~N}, \mathrm{~N}-$ bis(trimethylsylil) amines ${ }^{7}$ and $\operatorname{ArN}(\mathrm{MgBr})_{2} \cdot{ }^{8}$

In order to test other substrates during our recent study on [3,3] sigmatropic rearrangements promoted by dimethyl carbonate, ${ }^{9}$ we were interested in the preparation of the ketimine derivatives of aminoacetonitrile and glycine alkyl esters (1 and $\mathbf{3}$ ).

\footnotetext{
* To whom correspondence should be addressed
} 
However, starting from the available commercial aminoacetonitrile hydrochloride or glycine methyl ester salts, in the synthesis of derivatives $\mathbf{1}$ and $\mathbf{3}$ by the direct ketoneamine condensation, ${ }^{10-12}$ the free base $\left[\mathrm{NH}_{2} \mathrm{CH}_{2} \mathrm{Y} ; \mathrm{Y}=\mathrm{CN}\right.$ (1); COOMe (3)] has to be isolated and readily reacted; in addition, long reaction times at high temperatures and water azeotropic distillation are always required. Other simple methods reported for the reaction of glycine ethyl ester hydrochloride with 1,3-diketones ${ }^{13}$ and aldehydes ${ }^{14}$ give poor results when applied to ketones ${ }^{15}$. Also, the reported transimination reactions are a valuable alternative ${ }^{16}$, but the limit is the need of simple imines isolable only as diarylketone derivatives $\left(\mathrm{Ar}_{2} \mathrm{C}=\mathrm{NH}\right) .{ }^{17}$

We report here that, in the presence of DMF solvent and $\mathrm{TiCl}_{4}$, the dialkyl, alkylaryl and diaryl ketones can directly condense with functionalized primary amine hydrochlorides (4-6) to give the corresponding ketimines under mild reaction conditions (Eq. 1).

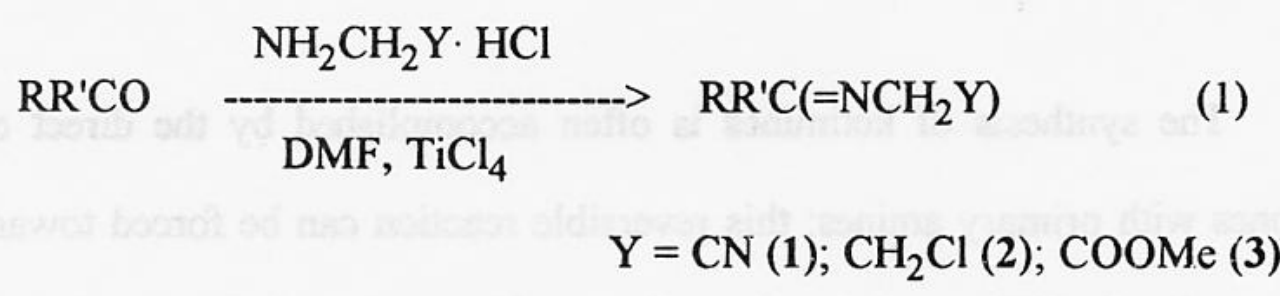

At first, the synthesis of derivatives 1 is considered. In the reaction of ketones with 4, the use of $\mathrm{TiCl}_{4}{ }^{1 \mathrm{a}, 2 \mathrm{a}}$ in the presence of $\mathrm{Et}_{3} \mathrm{~N}$, is very unsatisfactory when diethyl ether, hydrocarbons (benzene, hexane), THF or methanol are the solvents (for example, only $2-13 \%$ conversion is reached in the reaction of acetophenone with 4$)$. Indeed, we found that the solvent does play a crucial role: in fact, only in the presence of DMF, the reaction outcome dramatically changes: under mild conditions $\left(1 \mathrm{~h}\right.$ at $35{ }^{\circ} \mathrm{C}$ and $14 \mathrm{~h}$ at rt), ketones may quantitatively react to give the corresponding products 1 . Results are reported in the Table (entries 1-5) where two different conditions (A and B), referring to 


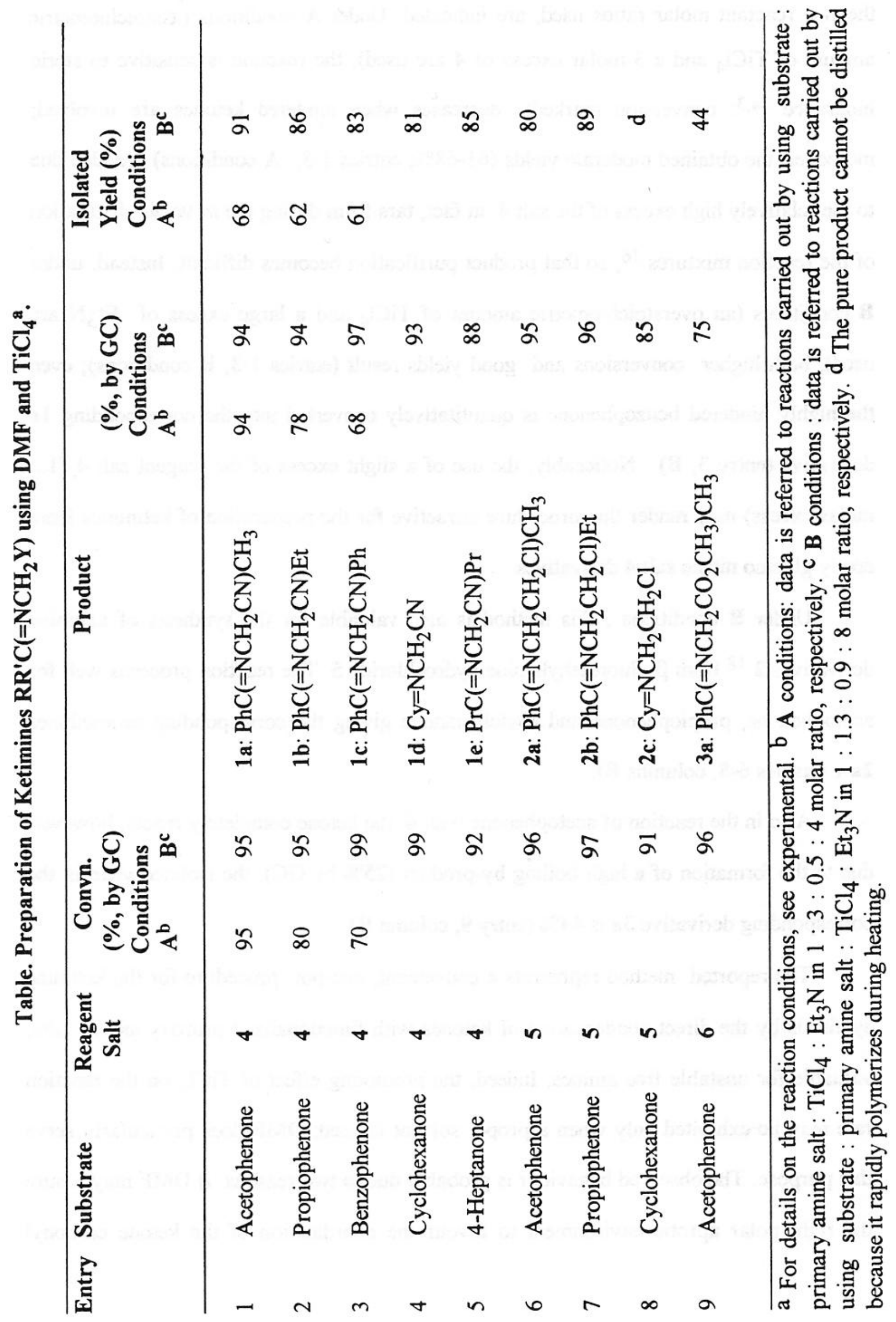


the two reactant molar ratios used, are indicated. Under $\mathbf{A}$ conditions (a stoichiometric amount of $\mathrm{TiCl}_{4}$ and a 3 molar excess of 4 are used), the reaction is sensitive to steric hindrance 2a,3: conversion markedly decreases when hindered ketones are involved; moreover, the obtained moderate yields (61-68\%; entries 1-3, A conditions) are also due to the relatively high excess of the salt 4 : in fact, tars form during the in vacuo distillation of the reaction mixtures ${ }^{16}$, so that product purification becomes difficult. Instead, under B conditions (an overstoichiometric amount of $\mathrm{TiCl}_{4}$ and a large excess of $\mathrm{Et}_{3} \mathrm{~N}$ are used), both higher conversions and good yields result (entries 1-3, B conditions); even the highly hindered benzophenone is quantitatively converted into the corresponding 1c derivative (entry 3, B). Noticeably, the use of a slight excess of the reagent salt 4 (1.3 molar excess) may render this procedure attractive for the preparation of ketimines from costly glycino nitrile salt 4 derivatives.

Under B conditions, this method is also valuable for the synthesis of ketimine derivatives $2^{18}$ from $\beta$-chloroethylamine hydrochloride 5 . The reaction proceeds well for acetophenone, propiophenone and cyclohexanone giving the corresponding azomethines 2a-c (entries 6-8, columns B).

Also in the reaction of acetophenone with 6, the ketone completely reacts; however, due to the formation of a high boiling by-product ( $25 \%$ by GC), the isolated yield in the corresponding derivative $3 \mathbf{a}$ is $44 \%$ (entry 9 , column B).

The reported method represents a convenient, one-pot procedure for the ketimine synthesis by the direct condensation of ketones with functionalized primary amine salts, valuable for unstable free amines. Indeed, the promoting effect of $\mathrm{TiCl}_{4}$ on the reaction rate may be exhibited only when a proper solvent is used: DMF does particularly serve this purpose. The observed behaviour is probably due to two reasons: i) DMF may assure the right polar aprotic environment to favour the coordination of the ketone carbonyl 
oxygen with the titanium atom ${ }^{1 a}$; ii) the reactant salts (4-6) are soluble in DMF ${ }^{19}$, but a white precipitate $\left(\mathrm{Et}_{3} \mathrm{NHCl}\right)$ rapidly forms when $\mathrm{Et}_{3} \mathrm{~N}$ is added so that, the acid-base equilibrium involving (4-6) and their conjugate bases $\left(\mathrm{NH}_{2} \mathrm{CH}_{2} \mathrm{Y}\right.$; 4a-6a) may be favourably shifted to the right: an increased concentration of the corresponding free amine nucleophiles (4a-6a) result in the reaction mixture. In fact, the reagent 4-6 are also wellsoluble in methanol but, contrary to DMF, an homogeneous solution is still observed after the addition of the $\mathrm{Et}_{3} \mathrm{~N}$. Other solvents are unefficient because they scarcely solubilize the salts 4-6.

In addition, appropriate reaction conditions allows the reaction to proceed also for highly hindered ketones.

\section{Experimental}

General. All compounds were ACS grade and were employed without further purification. Melting points were determined on a Buchi 535 melting point apparatus and are uncorrected. ${ }^{1}$ H NMR spectra were recorded on a Brucker $(200 \mathrm{MHz})$ spectrometer using $\mathrm{CDCl}_{3}$ with TMS as the internal standard. $\mathrm{GC}$ analyses were performed on a Varian GC 3300. GC/MS analyses were performed on a HP 5971 mass detector coupled to a HP 5890 gas chromatograph.

General Procedure for The Preparation of Ketimines 1-3 (Table, B Conditions). A mixture of the ketone, the amine hydrochloride salt (4-6), $\mathrm{Et}_{3} \mathrm{~N}$ (in $1: 1.3$ : 8 molar ratio, respectively) and DMF ( $7 \mathrm{~mL} / \mathrm{g}$ ketone) was loaded in a round-bottomed, two-necked flask fitted with a refluxing condenser and a dropping funnel both capped with $\mathrm{CaCl}_{2}$ tubes. A white precipitate $\left(\mathrm{Et}_{3} \mathrm{NHCl}\right)$ was rapidly formed; then, the suspension was thoroughly stirred magnetically for $30 \mathrm{~min}$ at $\mathrm{rt}{ }^{19}$. A n-pentane (1 M) solution of $\mathrm{TiCl}_{4}(0.9$ molar with respect to the substrate) was carefully added dropwise to the slurry ( $10 \mathrm{~mL}$ addition required $\sim 10 \mathrm{~min}$, being the reaction exothermic). After the 
addition was completed, the mixture was refluxed $\left(35-40^{\circ} \mathrm{C}\right)$ for $1 \mathrm{~h}$ and then allowed to stand $14 \mathrm{~h}$ at $\mathrm{rt}$. The suspension was poured into diethyl ether $(\sim 30 \mathrm{~mL} / \mathrm{g}$ substrate $)$ and stirred at rt for $40 \mathrm{~min}$ : a further precipitation occurring. Then, the solid was filtered and washed with diethyl ether. The light solvents (n-pentane and ether) and $\mathrm{Et}_{3} \mathrm{~N}$ were removed by rotary evaporation while DMF was distilled under vacuum $\left(\mathrm{bp}=48-50{ }^{\circ} \mathrm{C} / 20\right.$ $\mathrm{mm} \mathrm{Hg}$ ). The crude brown residue was recrystallized from n-pentane-diethyl ether (95: 5 $\mathrm{v} / \mathrm{v}$; products $\mathbf{1 a - c}$ and $\mathbf{3 a}$ ) or distilled (products 1d-e and $\mathbf{2 a - b}$ ).

Under A conditions, the reactions were carried out using the same procedure, but a different substrate: amine hydrochloride salt (4), $\mathrm{Et}_{3} \mathrm{~N}$ molar ratio was employed (1: $3: 4$ molar ratio, respectively).

The following data refers to ketimines 1-3 obtained according to $\mathbf{B}$ conditions.

N-(1-Phenylethylidene)-cyanomethylamine 1a. Starting from $2.0 \mathrm{~g}$ of aceto phenone, $2.4 \mathrm{~g}$ of $1 \mathrm{a}$ was isolated ( $99 \%$ pure by GC; $91 \%$ yield); mp $=38-40{ }^{\circ} \mathrm{C}$. ${ }^{1} \mathrm{H}$ $\operatorname{NMR}\left(\mathrm{CDCl}_{3}\right) \delta: 2.30\left(\mathrm{~s}, 3 \mathrm{H}, \mathrm{CH}_{3}\right), 4.40\left(\mathrm{~s}, 2 \mathrm{H}, \mathrm{CH}_{2}\right), 7.32-7.95(\mathrm{~m}, 5 \mathrm{H}, \mathrm{Ph})$. Mass spectrum (70 eV) $\mathrm{m} / z$ (relative intensity): $158\left(\mathrm{M}^{+}, 21\right), 157(56), 144(11), 143(100)$, $116(28), 103$ (43), 81 (10), 77 (15), 51 (11).

N-(1-Phenylpropylidene)-cyanomethylamine 1b. Starting from $3.0 \mathrm{~g}$ of propio phenone, $3.3 \mathrm{~g}$ of $1 \mathrm{~b}$ was isolated ( $98 \%$ pure by $\mathrm{GC} ; 86 \%$ yield); $\mathrm{mp}=45-46{ }^{\circ} \mathrm{C}$. ${ }^{1} \mathrm{H}$ NMR $\left(\mathrm{CDCl}_{3}\right) \delta: 1.15\left(\mathrm{t}, 3 \mathrm{H}, \mathrm{CH}_{3}\right), 2.75\left(\mathrm{q}, 2 \mathrm{H}, \mathrm{CH}_{2}\right), 4.45\left(\mathrm{~s}, 2 \mathrm{H}, \mathrm{CH}_{2}\right), 7.30-7.95$ (m, $5 \mathrm{H}, \mathrm{Ph})$. Mass spectrum $(70 \mathrm{eV}) \mathrm{m} / z$ (relative intensity): $172\left(\mathrm{M}^{+}, 12\right), 171(43), 144$ (12), 143 (100), $116(20), 103$ (37), 77 (11), 51 (7).

N-(1,1-Diphenylmethylidene)-cyanomethylamine 1c. Starting from $3.0 \mathrm{~g}$ of aceto phenone, $3.0 \mathrm{~g}$ of $1 \mathrm{c}$ was isolated $\left(97 \%\right.$ pure by $\mathrm{GC} ; 83 \%$ yield); $\mathrm{mp}=80-82{ }^{\circ} \mathrm{C}$ (Lit. 16 $\left.\mathrm{mp}=81-82^{\circ} \mathrm{C}\right) .{ }^{1} \mathrm{H} \mathrm{NMR}\left(\mathrm{CDCl}_{3}\right) \delta: 4.25\left(\mathrm{~s}, 2 \mathrm{H}, \mathrm{CH}_{2}\right), 7.12-7.75(\mathrm{~m}, 10 \mathrm{H}, 2 \mathrm{Ph})$. Mass spectrum $(70 \mathrm{eV}) \mathrm{m} / z$ (relative intensity): $220\left(\mathrm{M}^{+}, 58\right), 219(100), 193(25), 180(62)$, $166(10), 165(36), 116(25), 103(53), 77$ (31), $76(14), 51(22)$. 
N-Cyclohexylidene-cyanomethylamine $1 \mathrm{~d}^{20}$ Starting from $4.0 \mathrm{~g}$ of cyclo hexanone, $4.5 \mathrm{~g}$ of $1 \mathrm{~d}$ was isolated ( $95 \%$ pure by $\mathrm{GC} ; 81 \%$ yield); bp $=87-89^{\circ} \mathrm{C} / 0.1 \mathrm{~mm}$ Hg. ${ }^{1} \mathrm{H} \mathrm{NMR}\left(\mathrm{CDCl}_{3}\right) \delta: 1.35-1.85\left(\mathrm{~m}, 6 \mathrm{H}, 3 \mathrm{CH}_{2}\right), 2.15-2.35\left(\mathrm{~m}, 4 \mathrm{H}, 2 \mathrm{CH}_{2}\right), 4.15(\mathrm{~s}$, $\left.2 \mathrm{H}, \mathrm{CH}_{2}\right)$. Mass spectrum $(70 \mathrm{eV}) \mathrm{m} / z$ (relative intensity): $136\left(\mathrm{M}^{+}, 25\right), 135(11), 121$ (19), 108 (20), 107 (24), 94 (10), 93 (100), 80 (35), 67 (10), 66 (9), 53 (13).

N-(4-epthylidene)-cyanomethylamine 1e. Starting from $5.0 \mathrm{~g}$ of 4-heptanone, 5.6 $\mathrm{g}$ of $1 \mathrm{e}$ was isolated $\left(98 \%\right.$ pure by GC; $85 \%$ yield); bp $=72-74{ }^{\circ} \mathrm{C} / 0.1 \mathrm{~mm} \mathrm{Hg} .{ }^{1} \mathrm{H} \mathrm{NMR}$ $\left(\mathrm{CDCl}_{3}\right) \delta$ : 1.35 and $1.4\left(2 \mathrm{t}, 6 \mathrm{H}, 2 \mathrm{CH}_{3}\right), 1.35-1.6\left(2 \mathrm{q}, 4 \mathrm{H}, 2 \mathrm{CH}_{2}\right), 2.05-2.25(2 \mathrm{q}, 4 \mathrm{H}$, $\left.2 \mathrm{CH}_{2}\right), 4.15\left(\mathrm{~s}, 2 \mathrm{H}, \mathrm{CH}_{2}\right)$. Mass spectrum $(70 \mathrm{eV}) \mathrm{m} / \mathrm{z}$ (relative intensity): $152\left(\mathrm{M}^{+}, 1\right)$, 151 (1), 137 (28), 124 (33), 110 (16), 109 (100), 96 (94), 82 (31), 67 (26), 54 (7).

N-(1-Phenylethylidene)-2-chloroethylamine 2a. Starting from $2.0 \mathrm{~g}$ of acetophenone, $2.4 \mathrm{~g}$ of $2 \mathrm{a}$ was isolated ( $96 \%$ pure by $\mathrm{GC} ; 80 \%$ yield); bp $=103-105^{\circ} \mathrm{C}$ / $0.7 \mathrm{~mm} \mathrm{Hg}$. ${ }^{1} \mathrm{H} \mathrm{NMR}\left(\mathrm{CDCl}_{3}\right) \delta: 2.25\left(\mathrm{~s}, 3 \mathrm{H}, \mathrm{CH}_{3}\right), 3.70-3.80\left(\mathrm{~m}, 4 \mathrm{H}, 2 \mathrm{CH}_{2}\right), 3.85-$ $3.95\left(\mathrm{~m}, 4 \mathrm{H}, 2 \mathrm{CH}_{2}\right), 7.35-7.85(\mathrm{~m}, 5 \mathrm{H}, \mathrm{Ph})$. Mass spectrum $(70 \mathrm{eV}) \mathrm{m} / z$ (relative intensity): 183 (3), $181\left(\mathrm{M}^{+}, 9\right), 168$ (6), 166 (19), 146 (12), 132 (70), 104 (55), 103 (14), 91 (100), 77 (35), 65 (15), 63 (34), 51 (23). The colorless freshly-distilled product turned to yellow in few days even when stored at $0-4{ }^{\circ} \mathrm{C}$.

N-(1-Phenylpropylidene)-2-chloroethylamine 2b. Starting from $4.0 \mathrm{~g}$ of propiophenone, $5.2 \mathrm{~g}$ of $\mathbf{2 b}$ was isolated ( $99 \%$ pure by GC; $89 \%$ yield); bp $=88-90{ }^{\circ} \mathrm{C} /$ $0.3 \mathrm{~mm} \mathrm{Hg} .{ }^{1} \mathrm{H}$ NMR $\left(\mathrm{CDCl}_{3}\right) \delta: 1.15\left(\mathrm{t}, 3 \mathrm{H}, \mathrm{CH}_{3}\right), 2.75\left(\mathrm{q}, 2 \mathrm{H}, \mathrm{CH}_{2}\right), 3.70-3.80(\mathrm{~m}$, $\left.4 \mathrm{H}, 2 \mathrm{CH}_{2}\right), 3.85-3.95\left(\mathrm{~m}, 4 \mathrm{H}, 2 \mathrm{CH}_{2}\right), 7.35-7.85(\mathrm{~m}, 5 \mathrm{H}, \mathrm{Ph})$. Mass spectrum $(70 \mathrm{eV})$ $m / z$ (relative intensity): $197(3), 196(10), 195\left(\mathrm{M}^{+}, 9\right), 194$ (29), $168(20), 166(63)$, 146 (9), 117 (10), 105 (11), 104 (100), 103 (14), 91 (39), 77 (30), 65 (16), 63 (45), 51 (16). The pale yellow freshly-distilled product brownished in few days even when stored at $0-4^{\circ} \mathrm{C}$. 
N-Cyclohexylidene-2-chloroethylamine $2 c .{ }^{18}$ According to the above reported procedure, cyclohexanone $(5.0 \mathrm{~g})$ gave the corresponding $2 \mathrm{c}$ : at $91 \%$ conversion, $2 \mathrm{c}$ was $85 \%$ (by GC; the structure was confirmed by GC/MS); the product was not isolable by distillation because polymerization occurred during heating. Mass spectrum $(70 \mathrm{eV}) \mathrm{m} / \mathrm{z}$ (relative intensity): 161 (3), $159\left(\mathrm{M}^{+}, 10\right), 118$ (10), 116 (29), 110 (100), 105 (4), 103 (11), 81 (11), 65 (7), 63 (17), 54 (14)

Methyl N-(1-Phenylethylidene)-glycinate 3a. Starting from $2.0 \mathrm{~g}$ of acetophenone, $1.4 \mathrm{~g}$ of $3 \mathrm{a}$ was isolated ( $98 \%$ pure by GC; $44 \%$ yield); $\mathrm{mp}=54-56^{\circ} \mathrm{C}$. ${ }^{1}{ }_{\mathrm{H} \mathrm{NMR}}\left(\mathrm{CDCl}_{3}\right) \delta: 2.25$ (s, $\left.3 \mathrm{H}, \mathrm{CH}_{3}\right), 3.80$ (s, $\left.3 \mathrm{H}, \mathrm{CH}_{3}\right), 4.35$ (s, $\left.2 \mathrm{H}, \mathrm{CH}_{2}\right), 7.30-$ $7.85(\mathrm{~m}, 5 \mathrm{H}, \mathrm{Ph})$. Mass spectrum $(70 \mathrm{eV}) \mathrm{m} / \mathrm{z}$ (relative intensity): $191\left(\mathrm{M}^{+}, 7\right), 132(53)$, 118 (9), 103 (11), 91 (100), 77 (17), 51 (8).

Acknowledgments. This work was supported by MURST, fondo $60 \%$. Dr. Cristina Schiavon is gratefully acknowledged for her kind supply of NMR spectra.

\section{References}

1 (a) Weingarten, H.; Chupp, J. P. and White, W. A., J. Org. Chem., 1967, 32, 3246. (b) Layer, R., Chem. Rev., 1963, 63 , 489.

2 (a) Moretti, I. and Torre, G. Synthesis 1970, 141. (b) Carlson, R.; Larsson, U. and Hansson, L., Acta Chem. Scand., 1992, 46, 1211.

3 Stetin, C.; de Jeso, B. and Pommier, J. C., Synth. Commun., 1982, 12, 495.

4 Texier-Boullet, F., Synthesis, 1985, 679.

5 (a) Taguchi, K. and Westheimer, F. H., J. Org. Chem., 1971, 36, 1570.

(b) Roelofsen, D. P. and Van Bekkum, H., Recl. Trav. Chim. Pays Bas, 1972, 91, 605.

6 Eisch, J. J. and Sanchez, R., J. Org. Chem., 1986, $\underline{51}, 1848$.

7 Morimoto, M. and Sekiya, M., Chem. Lett., 1985, 1371. 
8 Okubo, M.; Hayashi, S.; Matsunaga, M. and Uematsu, Y., Bull. Chem. Soc. Jpn., $1981,54,2337$.

9 Selva, M.; Marques, C. A.; Tundo, P. and Montanari, F., J. Org. Chem., 1993, 58 , 5765 .

10 (a) Kametaka, N. et al., Ger. Offen., $D E .3,531,084$ (06 Mar 1986); Chem. Abstr., 1986, 105, 173046j. (b) O'Donnel, M. J.; Boniece, J. M. and Earp, S. E., Tetrahedron Lett., 1978, 30, 2641. (c) O'Donnel, M. J. and Eckrich, T. M., ibid., 1978, 47,4625 .

11 Cui Janguo and Yu Lingchong, Synth. Commun., 1990, 20, 2887.

12 Fieser, L. F. and Fieser, M., "Reagents for Organic Synthesis", Wiley, J. \& Sons, Inc. New York, 1967, Vol. 1; pp. 514, 959, 1014.

13 Hombrecher, H. K.; Horter, G., Synthesis, 1990, 389.

14 Luo, T., Ger. Offen. $D E$ 3,415,820 (31 Oct 1984); Chem. Abstr., 1985, 102, $113265 \mathrm{~h}$.

15 For example, we found that when acetophenone was reacted with 4 in the presence of $\mathrm{Et}_{3} \mathrm{~N}$ and $\mathrm{Na}_{2} \mathrm{SO}_{4}$, the better results was only $43 \%$ of ketone conversion after $15 \mathrm{~h}$ of reaction at $90^{\circ} \mathrm{C}$, in DMF solvent.

16 O'Donnel, M. J. and Polt, R. L., J. Org. Chem., 1982, 47, 2663.

17 March, J., "Advanced Organic Chemistry", Wiley, J. \& Sons, Inc. New York, $4^{\text {th }}$ Ed., 1992; pp. 896-7.

18 Tolstikov, G. A. et al., Izv. Akad. Nauk. SSSR, Ser. Khim., 1985, 10, 2174; Chem. Abstr. 1986, 104, 167681a.

19 The glycine methyl ester hydrochloride 6 was slightly soluble in DMF at $\mathrm{rt}$. The mixture was therefore stirred at $40{ }^{\circ} \mathrm{C}$ for $45 \mathrm{~min}$ : an evident, voluminous white 
precipitate appeared. Before adding the n-pentane solution of $\mathrm{TiCl}_{4}$, the suspension was cooled to rt.

20 Tsuge, O.; Ueno, K.; Kanemasa, S. and Yorozu, K., Bull. Chem. Soc. Jpn., 1986, $\underline{59}, 1809$.

(Received in The Netherlands 08 June 1994) 